Vol. 2, n. 3 - Edição Especial: Ciclos Formativos em Ensino de Ciências.

\title{
TRABALHANDO O CONCEITO DE DENSIDADE NA EDUCAÇÃO BÁSICA
}

\section{WORKING THE CONCEPT OF DENSITY IN BASIC EDUCATION}

\author{
Dalires Fatima Pezzini (dalirespezzini@ hotmail.com) \\ Universidade Federal da Fronteira (UFFS)
}

\begin{abstract}
Resumo: O presente relato foi vivenciado em um programa de iniciação à docência com foco no trabalho interdisciplinar na área de Ciências da Natureza. O objetivo da atividade realizada foi buscar ampliar as compreensões acerca do conceito de densidade dos alunos do nono ano do ensino fundamental. Além de instigá-los a discutir sobre o tema por meio de uma aula experimental, e com essa atividade, procurou-se estabelecer a relação entre o conteúdo e o cotidiano do aluno, a fim de propiciar uma melhor aprendizagem. $\mathrm{O}$ embasamento teórico foi discutido em sala de aula para que fosse demonstrada a relação da densidade com o volume e a massa. Em seguida, realizou-se, de forma coletiva, alguns questionamentos referentes à prática realizada, no qual os alunos relataram em quais situações cotidianas poderiam utilizar o conceito de densidade.
\end{abstract}

Palavras-chave: Experimentação; Densidade; Ensino de Ciências.

Abstract: The present report was experienced in a teaching initiation program focusing on interdisciplinary work in the area of natural sciences. The objective of this activity was to seek to broaden the understanding of the concept of density of ninth grade students. Besides encouraging them to discuss the subject through an experimental class, and with this activity, we sought to establish the relationship between the content and the student's daily life, in order to provide better learning. The theoretical basis was discussed in the classroom to demonstrate the relationship of density with volume and mass. Then, collectively, some questions regarding the practice were performed, in which students reported in which daily situations could use the concept of density.

Keywords: Experimentation; Density; Science teaching.

\section{INTRODUÇÃO}

Neste texto apresenta-se um relato de experiência realizado por meio de uma prática experimental que teve como temática o conceito de densidade. A atividade foi realizada em uma escola pública do município de Cerro Largo/RS, sendo desenvolvida por meio das ações realizadas no programa institucional de bolsa de iniciação à docência 


\title{
Vol. 2, n. 3 - Edição Especial: Ciclos Formativos em Ensino de Ciências.
}

- PIBID Interdisciplinar, vinculado à Universidade Federal da Fronteira Sul - UFFS, no ano de 2017.

Em relação ao conceito de densidade, parte-se da compreensão que este trata de um conceito unificador, conforme afirma Angotti (1993), "os conceitos unificadores podem aproximar as 'várias ciências', (dos cientistas, dos currículos, dos professores, dos alunos) preservando os níveis de formação e cognição".

Para abordar este conceito em aula, planejou-se a realização de uma atividade com foco na experimentação. Sendo que, as aulas experimentais, muitas vezes, assumem o papel de motivadora por promover a atividade e despertar a curiosidade do aluno, dando a ele possibilidade de fazer observações, descobrir, deduzir e tirar conclusões de forma contextualizada (CAMUENDO, 2006).

O uso de atividades experimentais visa proporcionar a aproximação da teoria e prática, buscando com que os alunos tornem-se mais participativos e interessados nas questões abordadas em sala de aula. Várias vezes, alguns professores, optam por não utilizar a experimentação em sala, isso pode ocorrer por motivos como a falta de tempo para elaborar uma aula baseada nessa perspectiva, seja pela falta de estrutura dos laboratórios de ciências. É importante ressaltar que as dificuldades cotidianas, a estrutura do laboratório e a falta de materiais não podem ser aceitas como justificativas plausíveis para extinguir a experimentação das aulas de ciências. Conforme apontam Zanon e Uhmann (2012),

\begin{abstract}
quando professores se limitam a lamentar a falta de laboratório na escola. Diferentemente do que certas pessoas pensam o laboratório qualificado não é a condição principal que vai aperfeiçoar o processo de ensinar e aprender ciências. O que custa caro é o estudante concluir a educação básica sem ter-se apropriado de conhecimentos escolares associados com observações frente a situações-problema e fenômenos, em atividades práticas de caráter investigativo (ZANON, UHMANN, 2002, p. 1).
\end{abstract}

Além disso, destaca-se a importância da reflexão do aluno diante a prática, pois é a partir dela o aluno tem maior possibilidades em associar o conteúdo a partir de diferentes visões. Destacando também o cuidado do professor em promover a prática investigativa e discutir as observações e anotações feitas pelos alunos. Nessa perspectiva, Zanon e Uhmann (2012) afirmam que

é fundamental auxiliar os estudantes, orientá-los em seus estudos, em seus processos de aprendizagem e de conhecimento. Mediar o acesso pedagógico aos conhecimentos científicos na escola implica zelar pelo avanço no raciocínio ao longo da realização das etapas de investigação, propiciar 
Vol. 2, n. 3 - Edição Especial: Ciclos Formativos em Ensino de Ciências.

processos de problematização e recontextualização dos objetos em estudo, intercalando observações e discussões teóricas. Isso, na medida em que os estudantes observam, registram, redigem observações e reelaboram seus processos de conhecimento e de reflexão (ZANON, UHMANN, 2002, p. 3)

Ainda, destaca-se a perspectiva de atividades experimentais de Schnetzler (2002), a qual afirma que as atividades experimentais são relevantes quando caracterizadas pelo seu papel investigativo e sua função pedagógica em auxiliar o aluno na compreensão de fenômenos. No ensino de química, especificamente, a experimentação deve contribuir para a compreensão dos conceitos e relacioná-los com o cotidiano, visto que as aulas experimentais, de uma forma geral, não necessitam ser realizadas em laboratórios com equipamentos sofisticados.

Nesse sentido, aponta-se a necessidade de buscar ações que promovam a realização de atividades experimentais nas aulas de Ciências com materiais alternativos de fácil aquisição e que estejam presentes no cotidiano do aluno.

\section{DESCRIÇÃO DAS ATIVIDADES}

A vivência relatada foi realizada em uma turma do $9^{\circ}$ ano do ensino fundamental de uma escola pública do município de Cerro Largo/RS. O planejamento foi elaborado pelas bolsistas do PIBID Interdisciplinar com o auxílio da professora de ciências da turma, num movimento colaborativo. Para a realização da prática utilizou-se um período de aula de 45 minutos.

Inicialmente realizou-se um diálogo com os alunos sobre as compreensões acerca do tema proposto, num movimento de retomada do conteúdo, tendo em vista que a professora titular de Ciências já havia explicado sobre a temática aula anterior, neste sentido compreende-se que foi possível ampliar e qualificar o diálogo.

A aula foi baseada em uma prática de fácil realização e com materiais do contexto dos alunos. Para tanto, não houve necessidade de deslocamento até o laboratório, considerando que o mesmo não se encontra em condições de uso. $\mathrm{O}$ experimento foi desenvolvido com a ajuda dos alunos, assim, eles puderam participar e auxiliar na realização da aula. Ainda, buscou-se apresentar para os eles como o conceito pode estar presente em seu cotidiano. 
Vol. 2, n. 3 - Edição Especial: Ciclos Formativos em Ensino de Ciências.

Os alunos participaram efetivamente de toda a atividade, a qual utilizou-se 7 béqueres, em cada um foram realizadas a mistura de diferentes substâncias, sendo elas: óleo e água; em outro água e arroz; água e isopor; água e um prego; glicose de milho, água e óleo; água e ovo cru; e sal dissolvido na água e um ovo cru.

$\mathrm{Na}$ sequência, os alunos foram orientados a descrever nos cadernos sobre os processos que ocorriam durante cada etapa da prática experimental. A partir da observação da figura apresentada a seguir.

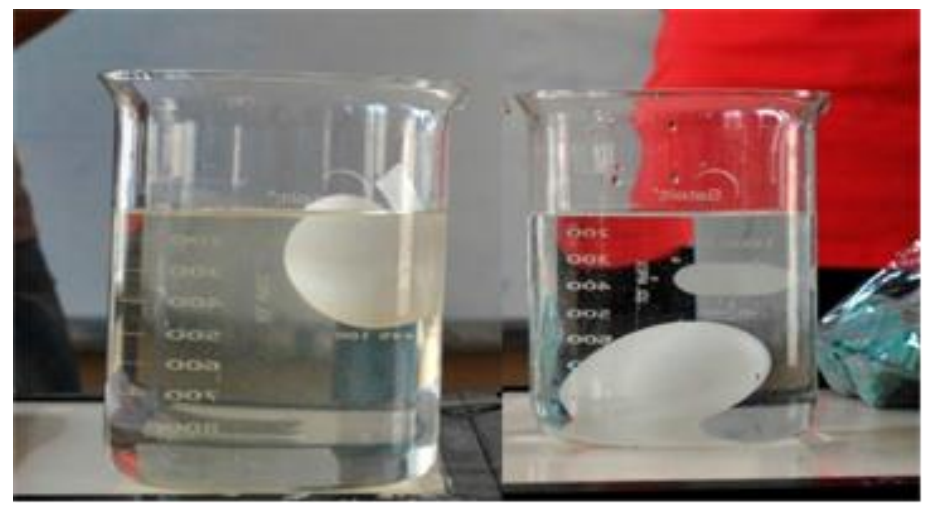

Figura 1 - Atividade prática

Após observarem a prática, cada aluno retornou para sua classe e responderam de forma coletiva alguns questionamentos referentes à prática realizada. O questionário contemplava as seguintes perguntas: Como podemos determinar a densidade de um sólido? O que são líquidos miscíveis e imiscíveis? Dê exemplos. Por que em um recipiente o ovo afundou e no outro recipiente não afundou? Explique. Durante a prática do óleo com a água, o que você percebeu? Explique qual é o mais denso. É possível determinar a densidade de um objeto sólido que tem massa de $20 \mathrm{~g}$ e um volume de $5 \mathrm{~mL}$ ? Demonstre: Por que a água e o óleo não se misturam? Tais questionamentos tiveram o objetivo de ampliar o diálogo e potencializar a compreensão acerca da relação entre a massa de um material e o volume por ele ocupado.

\section{DISCUSSÃO DA PRÁTICA}




\section{Vol. 2, n. 3 - Edição Especial: Ciclos Formativos em Ensino de Ciências.}

A realização da atividade em sala de aula auxiliou na desmistificação acerca da compreensão de que a experimentação tem espaço definido para ser realizada, ou seja, no laboratório. Ainda contribuiu para que a professora titular percebesse a importância do uso de materiais alternativos presentes no cotidiano dos alunos, para realizar o experimento, tornando-o mais acessível.

Partiu-se da compreensão que há muitas formas de ensinar e construir o conhecimento em sala de aula, porém cabe ao professor planejar e realizar práticas diferenciadas que estimulem o desenvolvimento do pensamento crítico e reflexivo dos alunos.

Por meio da experiência vivenciada, foi possível evidenciar a motivação dos alunos, pois a participação e colaboração mútua no processo foi muito significativa. Os diálogos dos alunos acerca da observação da prática da densidade possibilitaram com que eles permanecessem atentos e, assim, puderam compreender o conceito de densidade.

Além disso, a ênfase dada a presença do conceito de densidade na Biologia, na Física e na Química, contribuiu para que os alunos compreendessem aproximações entre as disciplinas. Identificou-se essas compreensões quando foi proposta uma discussão acerca da situação de um desastre ambiental, como no caso de derramamento de petróleo em alto mar. A partir dessa situação foi apresentada a questão biológica acerca da vida marinha, as substâncias químicas envolvidas e suas características e sobre o fenômeno físico que acontece.

Ainda, considerando que a densidade é um conceito que pode contribuir para os alunos compreenderem situações do seu dia a dia, a prática se mostrou mais atrativa para eles, dando-se ênfase para fatos que ocorrem cotidianamente. A motivação foi observada por meio dos relatos escritos pelos alunos. Isso foi percebido por meio do que um aluno expôs: "Eu achei uma experiência legal, pois não sabia que era por causa da densidade que o óleo flutua sobre os rios" (Aluno 1, 2017). Ainda, outro aluno afirmou: "Esta aula experimental me ajudou a entender que o óleo que flutua sobre a água dos rios e está poluindo o meio ambiente" (Aluno 2, 2017).

Os alunos demonstraram interesse em toda a atividade, o que contribuiu para que nós, enquanto bolsistas, identificássemos a importância da realização da experimentação 


\section{Vol. 2, n. 3 - Edição Especial: Ciclos Formativos em Ensino de Ciências.}

em sala de aula. No decorrer da aula foi identificada a colaboração e a interação de todos os alunos na observação e nas anotações.

Nessa perspectiva, Giordan (1999), argumenta que a experimentação pode ter um caráter indutivo e nesse caso, o aluno pode controlar variáveis e descobrir ou redescobrir relações funcionais entre elas, e pode também ter um caráter dedutivo quando eles têm a oportunidade de testar o que é dito na teoria, porém a utilização dessas atividades bem planejadas facilita muito a compreensão da produção do conhecimento em química, podendo incluir demonstrações feitas pelo professor, experimentos para confirmação de informações já dadas, cuja interpretação leve a elaboração de novos conceitos entre outros.

Nesse sentido, o diálogo e o questionamento são vistos como possibilidades importantes para a sala de aula capaz de promover a construção do conhecimento a partir de aprendizagens significativas. "[...] o que o professor deveria ensinar - porque ele próprio deveria sabê-lo - seria, antes de tudo, ensinar a perguntar. Porque o início do conhecimento, repito, é perguntar" (FREIRE, FAUNDEZ, 1985, p. 46). Assim, as dúvidas expressas por meio das perguntas representam inquietações resultantes do que se deseja aprender.

Em todo o processo educacional o professor ocupa um papel fundamental, de mediar o conhecimento e de instigar os estudantes sobre o que está sendo observado, nessa direção se enfatiza o fazer do professor e ressalta-se que há a necessidade do mesmo refletir sobre as suas ações e de conhecer as práticas, num movimento de olhar tanto os pontos positivos quanto os pontos negativos.

Além disso, ressalta-se a importância do diálogo estabelecido entre universidade e escola, entre professor e licenciando, na busca de novas práticas e interações nas aulas de Ciências.

\section{CONCLUSÃO}

Ao planejar as aulas de ciências de forma colaborativa compreende-se que devemos ter muito mais que um bom planejamento, também que não basta simplesmente 
Vol. 2, n. 3 - Edição Especial: Ciclos Formativos em Ensino de Ciências.

dominar o conteúdo específico. As situações vivenciadas na escola permitem identificar os desafios diários da docência.

Assim, considera-se importante a realização de práticas experimentais voltadas a um ensino interdisciplinar, pois essas ações possibilitam aos alunos espaços importantes para aprendizagem e interações com o cotidiano, permitindo uma ampla construção do conhecimento a partir da observação, do questionamento e da discussão.

\section{REFERÊNCIAS}

ANGOTTI, J. A. P. Conceitos Unificadores e o Ensino de Física. Revista Brasileira de Ensino de Fisica.v. 15, n.4, 1993.

CAMUENDO, A. P. L. A. Impacto das experiências laboratoriais na aprendizagem dos alunos no ensino de química. Dissertação (Mestrado em Educação) - Pontifícia Universidade Católica de São Paulo, São Paulo, 2006.

FREIRE, P.; FAUNDEZ, A. Por uma pedagogia da pergunta. Rio de Janeiro: Paz e Terra, 1985.

GIORDAN, M. O papel da experimentação no ensino de ciências. Química Nova na Escola, n. 10, p. 43-49, 1999. Disponível em: http://qnesc.sbq.org.br/online/qnesc10/pesquisa.pdf. Acesso em 31 de outubro de 2018.

SCHNETZLER, R. P. A Pesquisa em Ensino de Química no Brasil: Conquistas e Perspectivas. Química Nova, v. 25, s1, p.14, 2002. Disponível em: http://www.scielo.br/pdf/qn/v25s1/9408.pdf . Acesso em 12 de novembro de 2018.

ZANON, L. B.; UHMANN, R. I. M. O desafio de inserir a experimentação no ensino de ciências e entender a sua função pegagógica. ANAIS do XVI ENEQ. Disponível em: https://portalseer.ufba.br/index.php/anaiseneq2012/article/viewFile/8011/5716 Acesso em: 12 de novembro de 2018. 